Part of Journal of Research of the National Bureau of Standards, Volume 24, June 1940

\title{
INFLUENCE OF AUSTENITIC GRAIN SIZE ON THE CRITICAL COOLING RATE OF HIGH-PURITY IRON- CARBON ALLOYS
}

\author{
By Thomas G. Digges
}

\section{ABSTRACT}

A method is described for heating small specimens in vacuo and in an atmosphere of dry nitrogen to different temperatures and quenching directly in hydrogen. Determinations were made of the austenitic grain size and critical cooling rate of high-purity iron-carbon alloys ranging in carbon from 0.23 to 1.21 percent. These data show how carbon influences the austenitic grain size and critical cooling rate of the alloys and make possible a direct comparison of the relation of austenitic grain size to critical cooling rate, or hardenability.

\section{CON'TENTS}

I. Introduction

II. Alloys studied_._.

III. Experimental procedure

IV. Austenitic grain size

1. Previous investigations

2. Effect of rate of heating through the transformation range $\ldots$ - 729

3. Effect of temperature.

V. Critical cooling rate

VI. Influence of austenitic grain size and carbon content on the critical cooling rate.

VII. Surface hardness

VIII. Summary

IX. References

\section{INTRODUCTION}

The critical cooling rate, or hardenability, of a steel at the time of quenching depends primarily upon three factors, namely (1) chemical composition, (2) chemical homogeneity, and (3) grain size. The effect of carbon content on the rate of transformation of austenite in high-purity iron-carbon alloys and in plain carbon steels [1], ${ }^{1}$ and the influence of variations in chemical homogeneity on the mode and rate of transformation of austenite on quenching high-purity ironcarbon alloys [2], were discussed in previous reports. The present study was made to determine quantitatively the influence of grain size of the austenite on the critical cooling rate of the iron-carbon alloys.

1 Figures in brackets indicate the literature references at tbe end of this paper. $229032-40-9$ 


\section{ALLOYS STUDIED}

The high-purity iron-carbon alloys used in the present study ranged in carbon from 0.23 to 1.21 percent. The alloys were the same as those used in previous investigations, and their preparation was described in detail in a previous report [1]. Essentially, the procedure for preparing these alloys consisted in carburizing hot- and cold-worked specimens of high-purity iron in a mixture of hydrogen and benzene vapor and subsequently homogenizing by heating in vacuo at $1,700^{\circ} \mathrm{F}$. Cooling from the temperature used in homogenizing was sufficiently rapid to produce sorbite (fine pearlite) in all of the alloys. Specimens subsequently used for the determination of the austenitic grain size and critical cooling rate had this initial structure of sorbite. The method used in preparing the alloys eliminated the quality factor and variables other than carbon in composition.

The results of spectrochemical and chemical analyses, and the gas content as determined by the vacuum-fusion method for the ironcarbon alloys, are given in table 1. Sulfur, nickel, cobalt, and oxygen were the major impurities contained in the alloys. These elements amounted to about 0.021 percent, whereas the total percentage (by weight) of all impurities determined was about 0.030 .

TABLE 1.-Impurities determined in the iron-carbon alloys

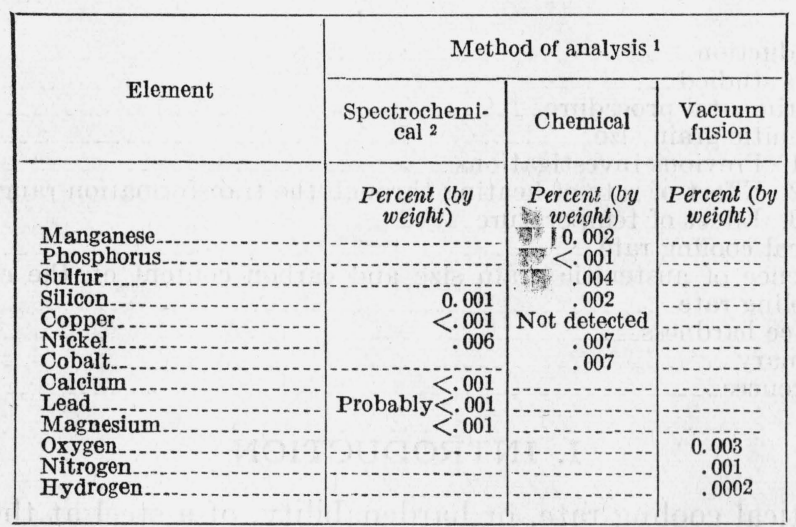

1 Determinations were made on specimens from the bars after carburizing and heat treatment for homogeneity, except as follows: Values of nickel, cobalt, and copper by chemical analysis were obtained from the electrolytic iron prior to melting and the values of manganese and phosphorus by chemical analysis were obtained from the bars as carburized. Spectrochemical analyses were made by B. F. Scribner, chemical analyses by W. H. Jukkola and J. L. Hague, and vacuum-fusion analyses by V. C. F. Holm, all members of the staff of the National Bureau of Standards.

2 Spectrum lines of cobalt and manganese were also found.

\section{EXPERIMENTAL PROCEDURE}

All the specimens used in the present investigation were approximately 0.10 inch square by 0.040 inch thick. One wire of a 32-gage Chromel-Alumel thermocouple was spot-welded to the center of one flat face of the specimen, and the other wire was spot-welded to the center of the opposite face. The specimens were heated in vacuo or in an atmosphere of dry nitrogen within a Chromel coil to the desired 


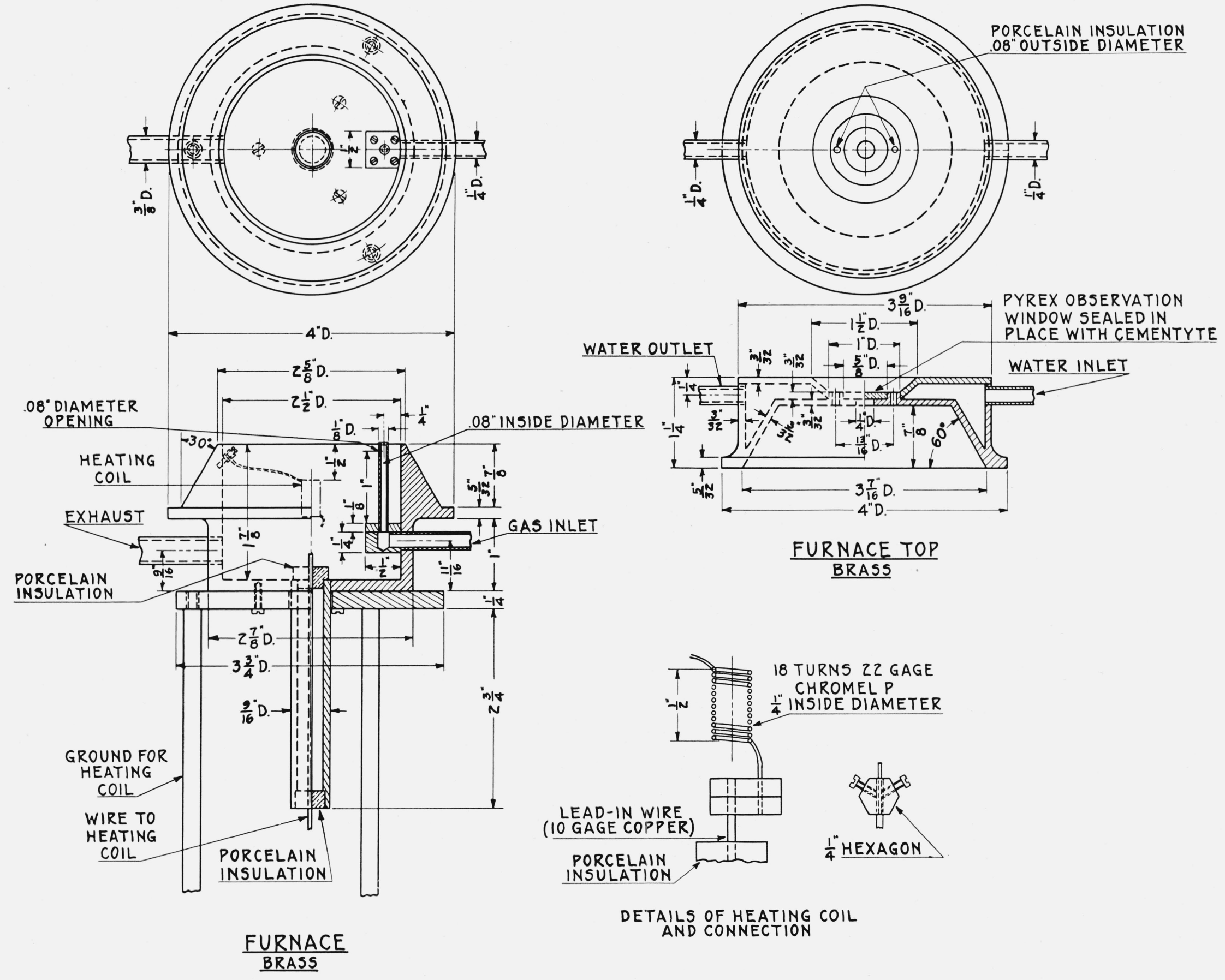

FIGURE 1.-Details of the construction of the furnace and heating coil for heating specimens in vacuo or in gas.

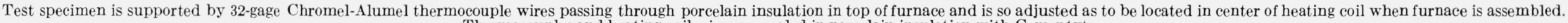
Thermocouples and heating-coil wires are sealed in porcelain insulation with Cementyte. 
temperature, and were held at that temperature for 15 minutes before cooling.

The specimens used in the determination of the austenitic grain size were cooled from the temperature establishing the grain size in a manner suitable for outlining the grains with proeutectoid ferrite or cementite, or troostite (fine pearlite). Grain-size measurements were made by the method described by Jeffries [3]. The specimens used in the determination of the critical cooling rate were quenched directly from the high temperatures in hydrogen. For correlating the critical cooling rate with microstructure, microscopic examination was made of the quenched specimens on the cross section of the 0.040 inch-thick sheet a short distance from the point of contact of the thermocouple wires.

Figure 1 shows the details of the construction of the furnace, and figure 2 shows the assembly of the apparatus used for heating the specimens either in vacuo or in dry nitrogen and quenching directly in hydrogen. The chamber $(E)$ containing the heating coil and the specimen was evacuated before heating the specimen. For heating the specimen in vacuo, the stopcocks $(C)$ to the hydrogen tank and $(B)$ to the nitrogen train were closed, and the stopcock $(D)$ to the vacuum pump was opened. For heating the specimen in nitrogen, the stopcock $(C)$ was closed, stopcock $(D)$ was opened only until the chamber was evacuated, and nitrogen was admitted into the evacuated chamber until the pressure within the chamber was slightly in excess of that of the atmosphere as shown by the mercury seal. The nitrogen was bubbled through butyl phthalate and over copper heated to $750^{\circ}$ to $800^{\circ} \mathrm{F}$., and dried by passing through Ascarite, magnesium perchlorate, and phosphorus pentoxide. The stopcock $(B)$ to the nitrogen train was closed prior to heating the specimen. At the time of quenching the specimen heated either in vacuo or nitrogen, the stopcocks $(D)$ and $(B)$ were closed, and the switch $(A)$ was opened and the stopcock $(C)$ turned to permit passage of hydrogen into the heating chamber. The hydrogen, after passing around the specimen, was exhausted into the air through the mercury seal. The desired cooling rates were obtained by regulating the flow of gas with reducing and needle valves attached to the hydrogen tank, and by changing the position of a gas nozzle within the chamber. With a selected rate of flow of hydrogen, higher cooling rates were obtained when the outlet of the nozzle was directly below the heating coil containing the specimen than when the nozzle was in the side position, shown in figure 1. After the heating chamber was partially evacuated, three "C" clamps (not shown in figs. 1 and 2) were used to clamp together the top and bottom sections of the furnace. This procedure aided in obtaining a tight seal with the stopcock grease used along the tapered surfaces of the furnace, and also prevented the furnace top from lifting during the time of quenching. Stopcocks $B, C$, and $D$ were specially ground to prevent leakage, and a liquid air trap was used between the furnace and the mercury-diffusion pump.

WWith the present equipment and with the use of gases as the quenching media, it was possible to heat the specimens in vacuo or dry nitrogen at various rates to different temperatures and to quench directly from these temperatures without moving the specimens. 


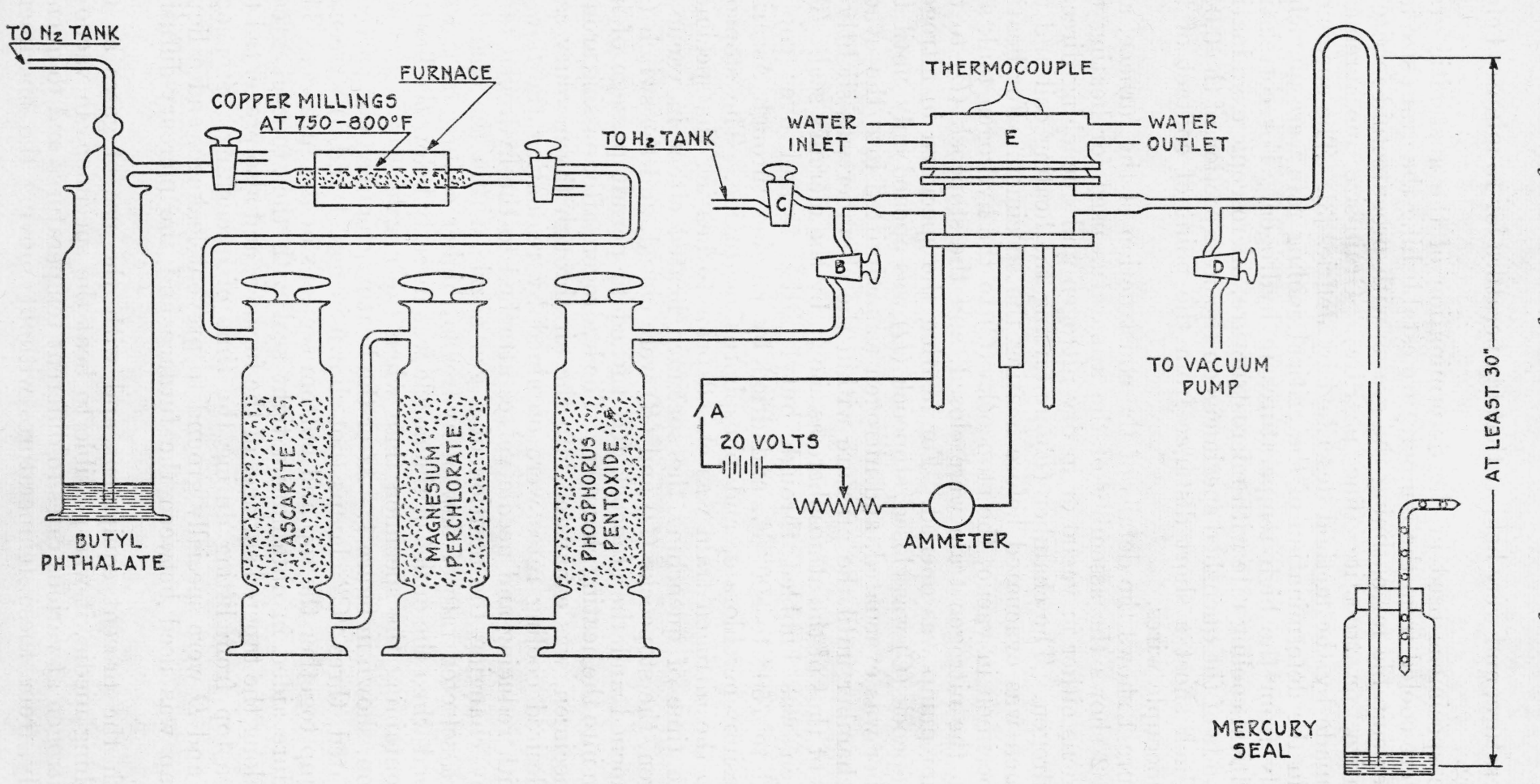



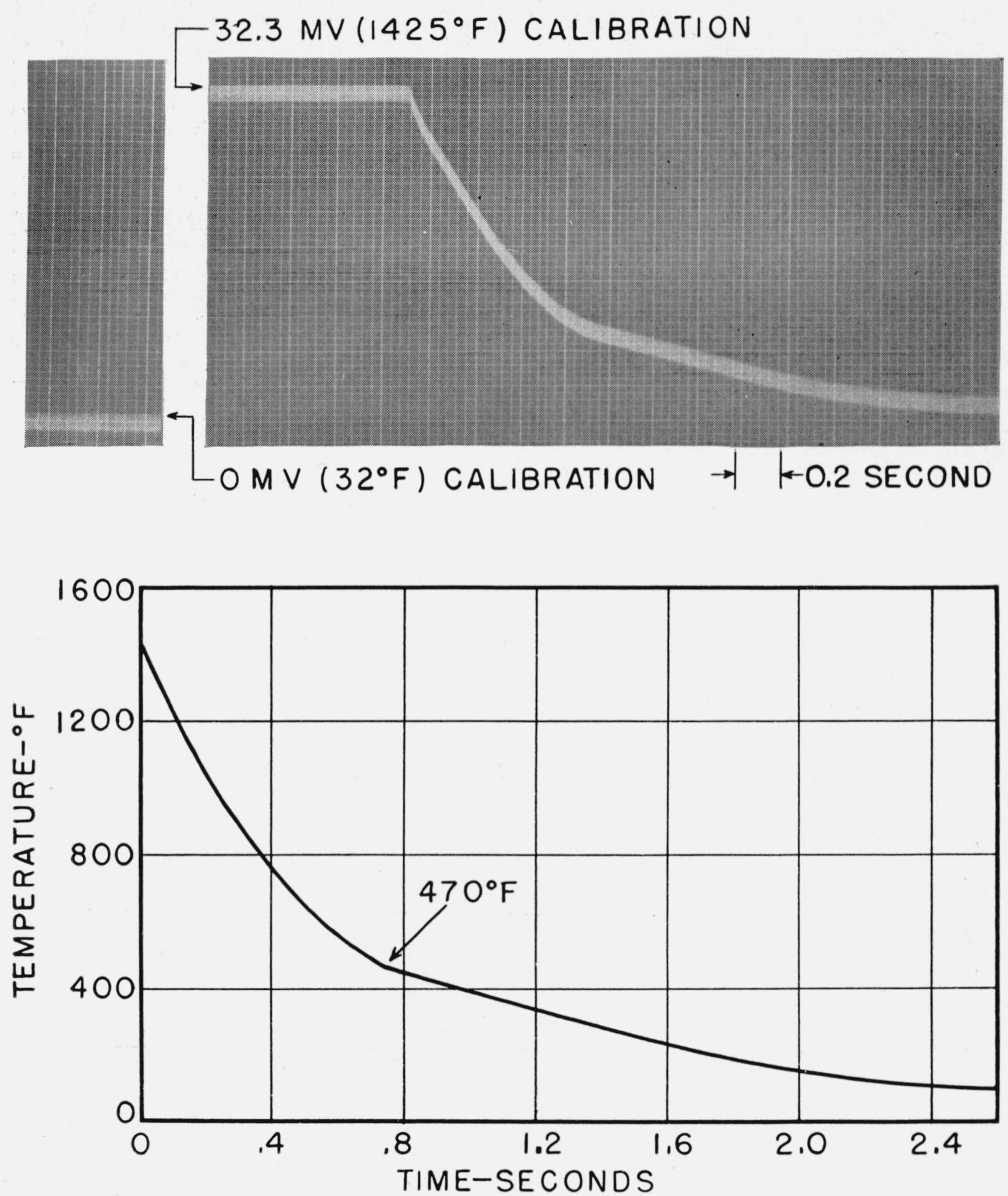

FIGURE 3.-Photographic record obtained with the string galvanometer apparatus and plotted time-temperature cooling curve.

Specimen of the alloy containing 0.85 percent of earbon heated in an atmosphere of dry nitrogen and quenched directly in hydrogen at about its critical cooling rate. 

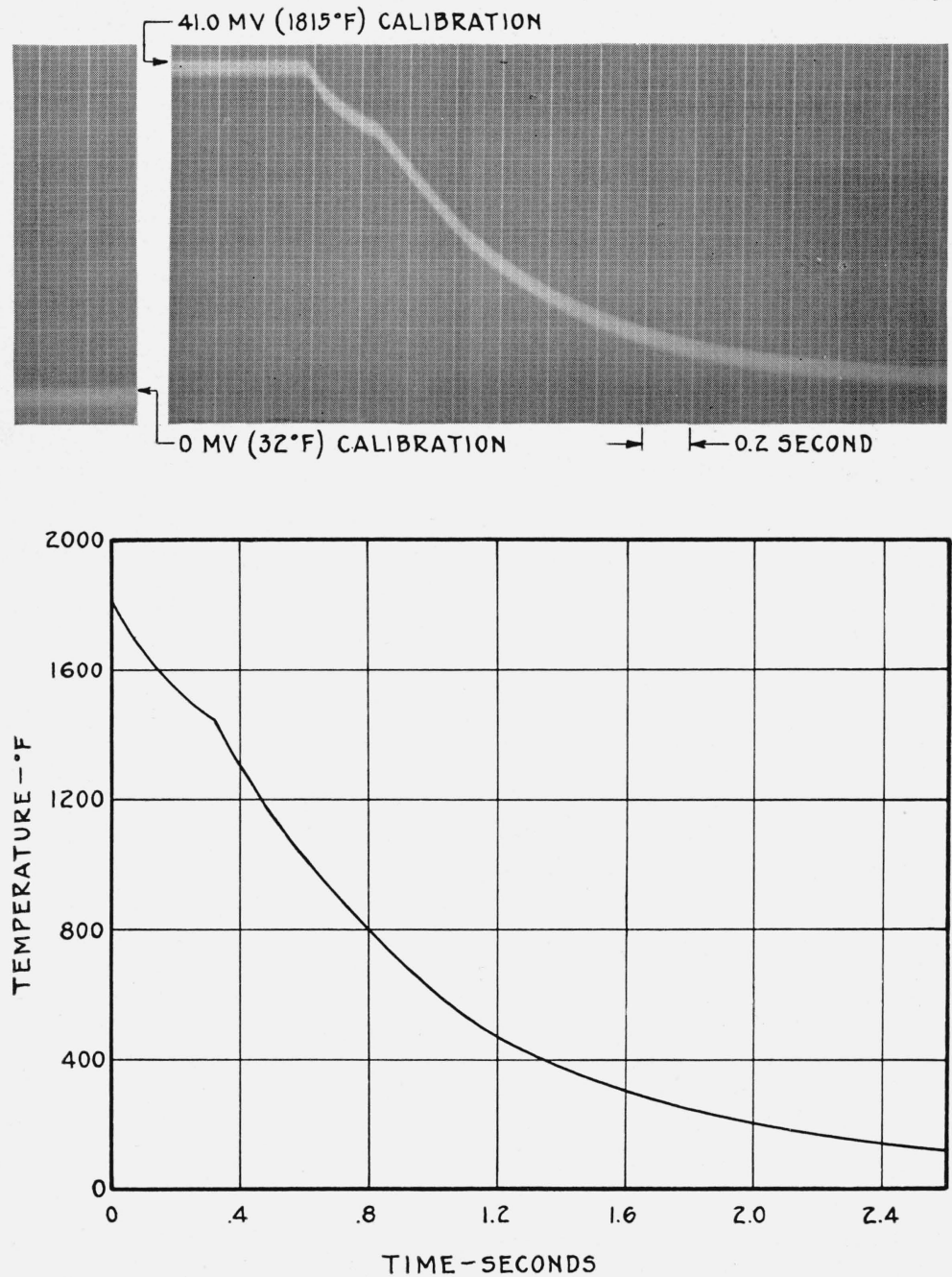

FIGURE 4.-Photographic record obtained with the string galvanometer apparatus and plotted time-temperature cooling curve.

Platinum specimen heated in vacuo and quenched directly in hydrogen. 
Oxidation of the specimen during the time of heating and quenching was eliminated, and progressive changes in cooling rates were obtainable over the wide range required in the present experiments. The structure produced in the quenched specimens indicated that they were cooled uniformly over the entire surface.

Preliminary tests were carried out to determine whether specimens of high-purity iron were contaminated with aluminum, chromium, and nickel in the process of spot-welding the Chromel-Alumel thermocouple, or during the time of heating the specimens to high temperatures in contact with this couple within a Chromel coil in vacuo. Spectrochemical analysis made on these specimens after removing: 0.002 to 0.003 inch from the original surfaces showed no indication of aluminum or chromium, and only a small increase in nickel incident to these treatments.

For the determination of the critical cooling rates, a photographic time-temperature cooling curve was obtained during the quench by means of a string-galvanometer apparatus, in the manner previously described by French \& Klopsch [4]. The string galvanometer used consisted of a fine tungsten wire suspended in a strong magnetic field. When this galvanometer is connected to a source of electromotive force, which in this case is a thermocouple, a deflection of the string is obtained which is proportional to the current in the string circuit. Provided the resistance of the string circuit and the strength of the magnetic field remain constant, deflections of the string are directly proportional to the electromotive force and these deflections may be converted into temperature equivalents. The shadow of the string is projected, at about 500 magnification, upon a moving photographic film of bromide paper, $2 \frac{3}{8}$ inches wide, thus giving a continuous record of variations in temperature during the quench. Time intervals are recorded on the film by interrupting the beam of light with a slotted disk rotated at a constant speed by means of a synchronous motor operated from a tuning fork. A continuous time-temperature cooling curve could be plotted from the data recorded on the film.

Calibration of this apparatus was carried out before each quench by recording on the film the zero position of the string, corresponding: to open circuit of the thermocouple (zero emf), and the position of the string when the known emf of the thermocouple corresponding to the quenching temperature was applied (figs. 3 and 4). The emf of the thermocouple corresponding to the quenching temperature was determined with a potentiometer indicator. Change in resistance of the galvanometer circuit resulting from cooling a short length of the thermocouple wires during the time of quenching was relatively small in comparison with the total resistance of the circuit. This variation in resistance was well within the limit of experimental error and could be neglected.

Figure 3 shows a photographic record and plot of a time-temperature cooling curve obtained on a specimen of the 0.85 -percent-carbon alloy heated in an atmosphere of dry nitrogen to $1,425^{\circ} \mathrm{F}$ and quenched directly in hydrogen at about its critical cooling rate. No arrest appeared in the cooling curve until the temperature of the specimen had fallen to about $470^{\circ} \mathrm{F}$. At approximately this temperature the austenite started to transform to martensite $\left(A r^{\prime \prime}\right)$. The $A r^{\prime \prime}$ transformation, however, was not clearly shown in the photographic records 
obtained on quenching the relatively stable austenite of the hypereutectoid alloys. With the hypereutectoid alloys, the $A r^{\prime \prime}$ occurred at temperatures below the arrest shown in figure 3, a factor that made difficult its detection.

A photographic record and a plot of the time-temperature curve obtained on a platinum specimen heated in vacuo to $1,800^{\circ} \mathrm{F}$ and quenched directly in hydrogen are shown in figure 4. There was an arrest in the cooling curve at about $1,450^{\circ} \mathrm{F}$, or about $350^{\circ} \mathrm{F}$ below the temperature at the start of the quench. The arrest, obviously, was not due to a heat evolution caused by a structural change in the platinum specimen. This high-temperature arrest was observed in the cooling curves of all the specimens heated in vacuo and rapidly quenched directly in hydrogen, but it was not observed in the specimen heated in an atmosphere of nitrogen and similarly quenched. The arrest was therefore characteristic of the procedure used in heating in vacuo and quenching directly in hydrogen, and was probably due to the variation in rate of flow of the quenching gas around the specimen during a short interval at the start of the quench. Such an arrest in the cooling of specimens by heating in vacuo and quenching directly in hydrogen has no appreciable effect on the rate of transformation of austenite, provided the quenching temperature is sufficiently high for the lag to occur above or in the vicinity of $A e_{1}$. With quenching temperatures just above $A e_{1}$, the arrest may occur in the upper range in which austenite is least stable $\left(1,110^{\circ}\right.$ to $\left.930^{\circ} \mathrm{F}\right)$ and thus have an influence in the formation of the decomposition products of austenite of high transformation rate. To eliminate this factor in the determination of the critical cooling rate, the specimens quenched directly from temperatures just above $A e_{1}$ were heated in an atmosphere of dry nitrogen.

As shown in figure 4, no arrest occurred on cooling the platinum specimen through the temperature range below $950^{\circ} \mathrm{F}$. With highpurity iron-carbon alloys containing carbon in excess of 0.20 percent, the transformation of austenite to martensite begins at temperatures below $950^{\circ} \mathrm{F}$.

\section{AUSTENITIC GRAIN SIZE}

\section{PREVIOUS INVESTIGATIONS}

Reviews of some of the most important works on the subject of austenitic grain size have recently been prepared by Shapiro [5] and by Ward and Dorn [6]. Shapiro states that "The final austenitic grain size of any steel is influenced by: (1) prior structure or initial grain size, (2) mechanical deformation (hot and cold work) which remains or is conferred upon it during austenitizing, (3) the rate of heating to the austenitic condition, (4) time and temperature of heating $\left(T^{\max }\right)$, (5) method of deoxidation, and (6) the type of inhibitors resulting from the deoxidization process. These factors may either intensify or minimize one another's effects and thereby may either refine or increase the austenitic grain size, depending on whether they act in a like or opposite manner."

Derge, Kommel, and Mehl [7] have investigated some of the factors influencing austenitic grain size in high-purity steels. They conclude that " $\mathrm{Al}_{2} \mathrm{O}_{3}$ and $\mathrm{SiO}_{2}$ inhibit grain growth; whereas aluminum and silicon in solid solution do not, and that the degree of inhibition is closely related to the type of dispersion of the oxides." Grossmann 


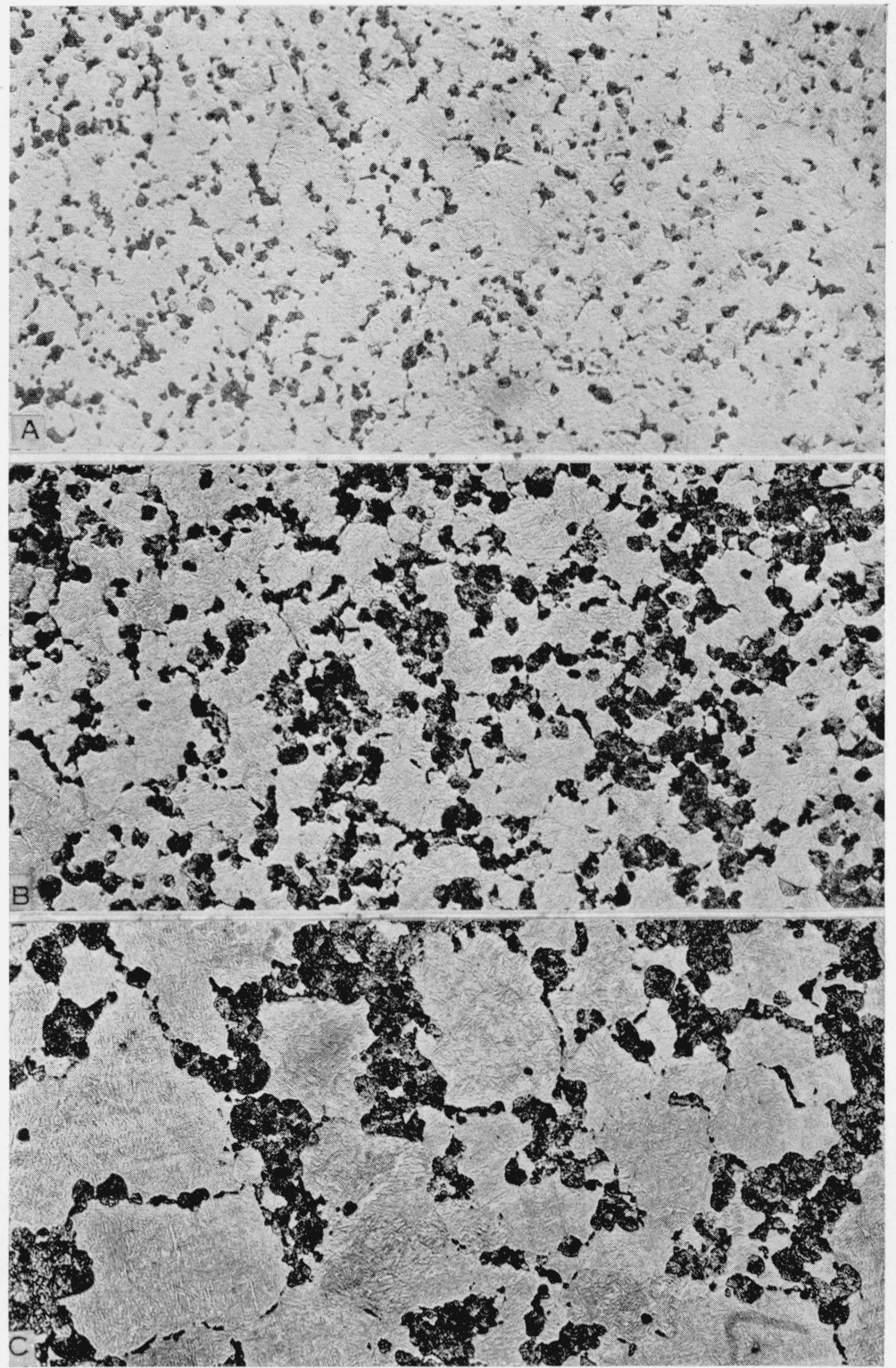

FIGURE 5.-Effect of rate of heating through the transformation range on the grain size at $1,425^{\circ} \mathrm{F}$ of iron-carbon alloy containing 0.73 percent of carbon.

$A$, Heated rapidly in lead bath at $1,425^{\circ} \mathrm{F}$; approximately 40 grains per square inch at 100 diameters. $B$, Heated from $70^{\circ}$ to $1,400^{\circ} \mathrm{F}$ in 1 minute; approximately 20 grains per square inch at 100 diameters. $C$, Heated from $70^{\circ}$ to $1,415^{\circ} \mathrm{F}$ in $2 \frac{1}{2}$ minutes; approximately 5 grains per square inch at 100 diameters. Etched with 1-percent nital. $\times 100$. 

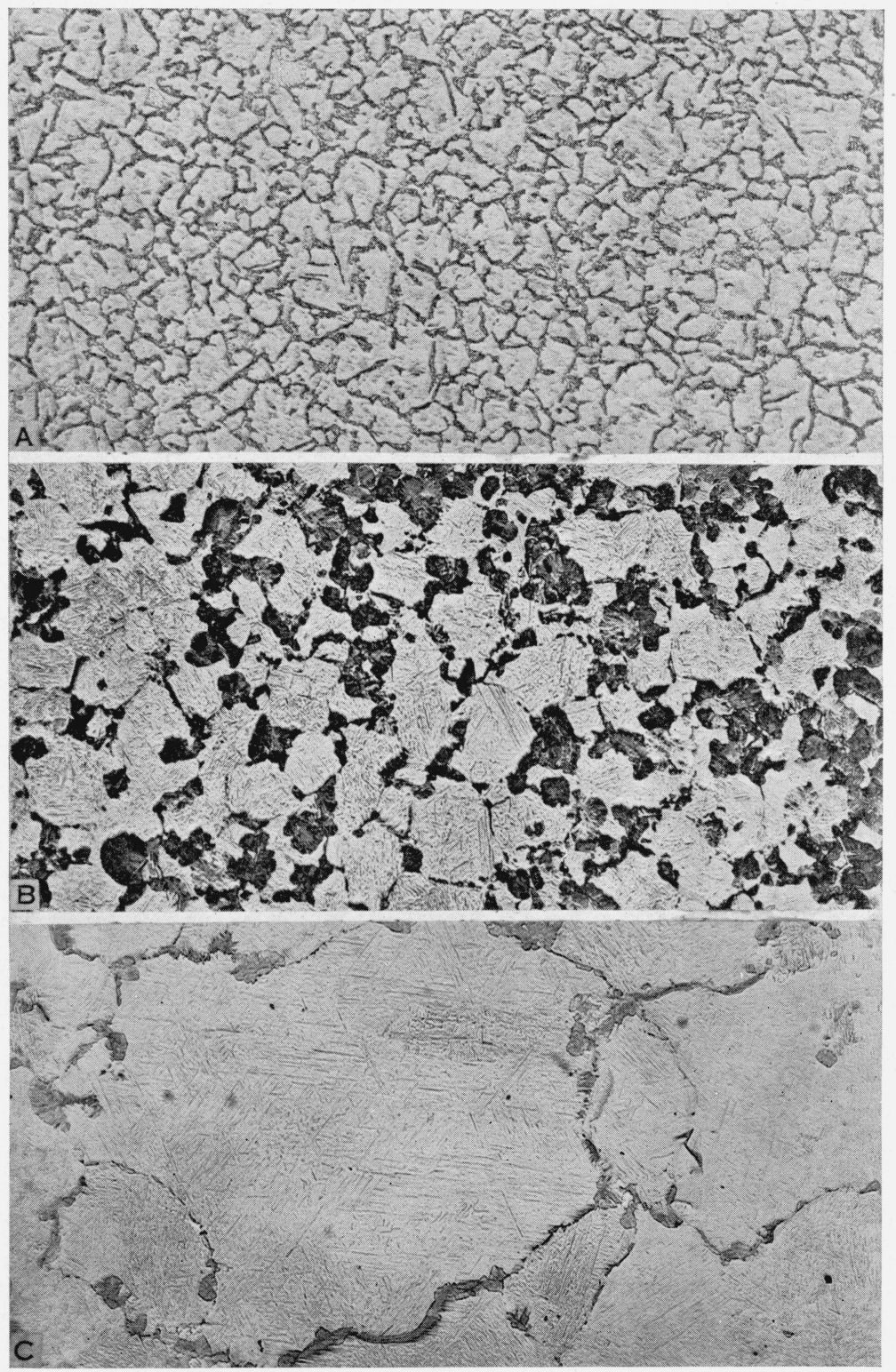

FIGURE 6.-Effect of rate of heating through the transformation range on the grain size at $1,600^{\circ} F$ of iron-carbon alloy containing 0.50 percent of carbon.

$A$, Heated rapidly in lead bath at $1,600^{\circ} \mathrm{F}$; approximately 50 grains per square inch at 100 diameters. $B$, Heated from $70^{\circ}$ to $1,590^{\circ} \mathrm{F}$ in 51 seconds; approximately 15 grains per square inch at 100 diameters. $C$, Heated from $70^{\circ}$ to $1,415^{\circ} \mathrm{F}$ in $21 / 2$ minutes; approximately 1 grain per square inch at 100 diameters.

Etched with 1-percent nital. $\times 100$. 


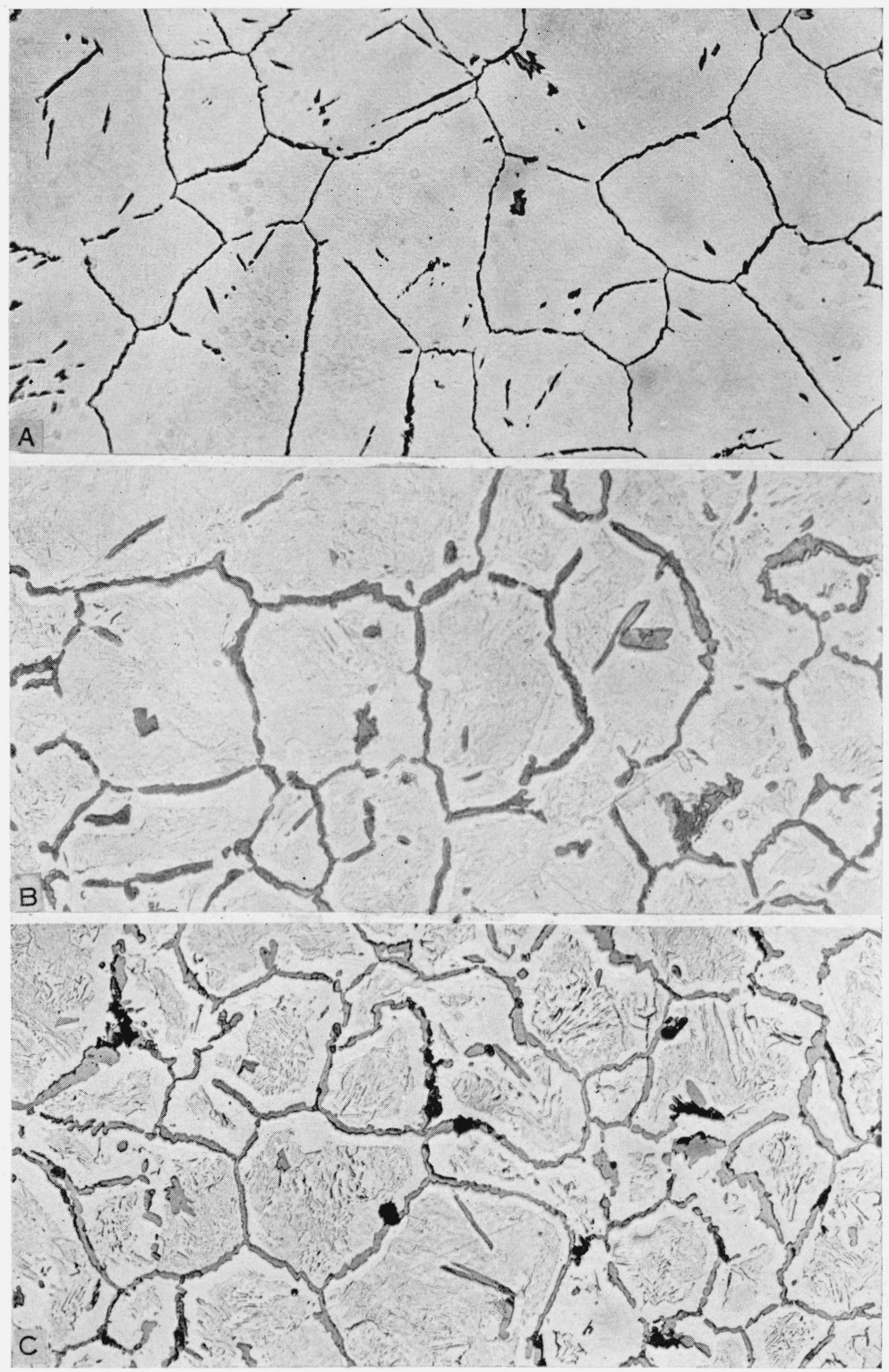

FIGURE 7.-Effect of rate of heating through the transformation range on the grain size at $1,800^{\circ} \mathrm{F}$ of iron-carbon alloy containing 1.21 percent of carbon.

$A$, Heated from $70^{\circ}$ to $1,750^{\circ} \mathrm{F}$ in 1 minute; approximately 2.2 grains per square inch at 100 diameters. $B$, Heated from $1,330^{\circ}$ to $1,370^{\circ} \mathrm{F}$ in 24 minutes; approximately 2.3 grains per square inch at 100 diameters. $C$,

Heated from $1,330^{\circ}$ to $1,370^{\circ} \mathrm{F}$ in $381 / 2$ minutes; approximately 3.2 grains per square inch at 100 diameters. Etched with boiling sodium picrate. $\times 100$. 
[8] has discussed the mechanism of grain growth in low-carbon steels during carburization. He shows that upon heating a low-carbon steel, the first austenite appears at the interfaces of the ferrite and carbide. As the temperature of heating is increased, the austenite begins to encroach on the ferrite grains and proceeds until the steel is completely transformed to austenite.

\section{EFFECT OF RATE OF HEATING THROUGH THE TRANSFORMATION RANGE}

Specimens of the high-purity iron-carbon alloys were heated at various rates through the transformation range to temperatures ranging from $1,425^{\circ}$ to $1,800^{\circ} \mathrm{F}$. The grain sizes obtained with the different rates of heating for the 0.73 -percent-carbon alloy at $1,425^{\circ} \mathrm{F}$ are shown in figure 5 , for the 0.50 -percent-carbon alloy at $1,600^{\circ} \mathrm{F}$ in figure 6 , and for the 1.21-percent-carbon alloy at $1,800^{\circ} \mathrm{F}$ in figure 7 . The grain size established at temperatures ranging from $1,425^{\circ}$ to $1,600^{\circ} \mathrm{F}$ increased markedly with decrease in rate of heating these high-purity alloys, whereas the grain size at $1,800^{\circ} \mathrm{F}$ was not so noticeably dependent upon the rate of heating. Additional data on this subject will be presented in a subsequent report.

\section{EFFECT OF TEMPERATURE}

The grain sizes at temperatures ranging from $1,425^{\circ}$ to $2,100^{\circ} \mathrm{F}$ were determined for the alloys, and the results are summarized in table 2. Although the specimens were heated at a rapid rate through the transformation range, this rate was not precisely the same for all the specimens. With the heating rate employed and with complete solution of carbon, all the alloys had approximately the same average grain size at any selected temperature within the range of $1,600^{\circ}$ to $2,100^{\circ} \mathrm{F}$. At temperatures of $1,425^{\circ}$ and $1,500^{\circ} \mathrm{F}$, some variations were observed in the average grain size of the different alloys, which were probably due to small differences in rate of heating or to masking of some of the smaller size grains by coalescence of the constituent used in outlining the parent austenite grain.

TABLE 2.-Austenitic grain size of the iron-carbon alloys

[The specimens, $1 / 10$ inch square by 0.040 inch thick, were heated rapidly in vacuo or in an atmosphere of dry nitrogen to temperatv*es indicated, held at temperature for 15 minutes, and then cooled in a manner suitable for outlining the grains. In general, each grain-size value reported is the average of four determinations made on one specimen]

\begin{tabular}{|c|c|c|c|c|c|c|c|c|c|c|c|c|}
\hline \multirow{2}{*}{$\begin{array}{l}\text { Car- } \\
\text { bon }\end{array}$} & \multicolumn{12}{|c|}{ A verage number of grains per square inch at 100 diameters at various temperatures, ${ }^{\circ} \mathrm{F}$} \\
\hline & 1,425 & 1,500 & 1,550 & 1,600 & 1,650 & 1,700 & 1,750 & 1,800 & 1,900 & 2,000 & 2,050 & 2,100 \\
\hline $\begin{array}{c}\% \\
0.23\end{array}$ & & & & & & $\mathrm{a}(8)$ & & $2.2,2.2$ & & 1.1 & & 0.8 \\
\hline $\begin{array}{l}.40 \\
.50\end{array}$ & & 12 & & $12,9,7$ & & $\ldots$ & & $\begin{array}{l}2.3,2.7 \\
2.3,3.0\end{array}$ & & 1.1 & & -1.0 \\
\hline .62 & 13,15 & 10,8 & & 9 & & $8,(8),(8)$ & & $2.2,3.2,3.7 \cdot 3 \cdot 5$ & & & & 1.5 \\
\hline .73 & 23 & 17 & & 13,12 & & & & $\begin{array}{l}2.6,2.5,2.7,3.5 \text {, } \\
3.5,3.0 .\end{array}$ & & & 1.6 & $\cdots$ \\
\hline $\begin{array}{l}.80 \\
.85\end{array}$ & & $\begin{array}{l}25 \\
17\end{array}$ & 14 & 11 & & & & $\begin{array}{l}3.0,2.7 \\
2.8\end{array}$ & & 8 & & $\cdots$ \\
\hline 1. 01 & & & ...... & $16,15,10$ & & $6,(8)$ & & 3.1 & 2.1 & $\begin{array}{l}.8 \\
1.6\end{array}$ & -- & {$[-\cdots$} \\
\hline 1. 14 & & & & & 9 & $6,7,(9)$, & 4 & 3.1 & 2.1 & 1.9 & |- & $\cdots$ \\
\hline 1.21 & & & & & & $9,(9)$ & & $\begin{array}{c}2.8,1.9,2.3,2.7 \text {, } \\
3.5,3.1,3.7 .\end{array}$ & & & & ....... \\
\hline
\end{tabular}

a The values appearing in parentheses were obtained in a previous investigation [1] on specimens $1 / 4$ inch square by 0.040 inch thick, heated rapidly in dry nitrogen. 
Carbon was the only element present in these alloys in a sufficient amount that might be considered in the class of grain-growth inhibitors. At temperatures required for complete solution in austenite (that is, above $A c_{3}$ or $A c_{m}$ ), carbon evidently is not effective in inhibiting grain growth in high-purity iron-carbon alloys. For example, at $1,700^{\circ} \mathrm{F}$ each of the alloys ranging in carbon from 0.23 to 1.21 percent had an average grain size of about 6 to 9 grains per square inch at 100 diameters. This temperature is only slightly above the $A_{c m}$ for the 1.21-percent-carbon alloy, whereas it is approximately $370^{\circ} \mathrm{F}$ in excess of the temperature required for complete solution of carbon in the alloy of eutectoid composition. The actual temperature $\left(T_{\max }\right)$ and the rate of heating through the transformation range were the dominant factors in controlling the austenitic grain size of these alloys.

\section{CRITICAL COOLING RATE}

Davenport and Bain [9], and coworkers [10], in their studiess of the process and results of the transformation of austenite at constant temperatures, showed that the structure and hardness of a quenched steel depend primarily on the particular temperature at which the austenite decomposes during quenching. The general form of the transformation temperature-time curve (the so-called S-curve when temperature is plotted on Cartesian and time on a logarithmic basis) was the same for all steels investigated, but there were significant differences in the position of the S-curve on the time scale and minor differences on the temperature scale. Their results showed that the hardenability of a steel depends upon the stability of the quenched austenite in the temperature range of about $1,110^{\circ}$ to $930^{\circ} \mathrm{F}$, the upper bend of the S-curve, figure 8. This is the upper range in which austenite is most likely to decompose and in which its decomposition products are relatively soft. If by a continuous quench to room temperature the austenite is cooled through this temperature range without decomposing (figure 8, curve $A$ ), it transforms only in the temperature range below about $300^{\circ} \mathrm{F}$ and the product of decomposition is martensite. If the austenite is cooled at a slower rate through this upper temperature range (curve $C$ ), part of the austenite transforms in this temperature range to troostite (fine pearlite) and the remaining austenite is cooled unchanged to the temperature favorable for its decomposition to martensite. At some cooling rate, called the critical cooling rate, the austenite just begins to decompose (curve $B$ ), in the range $1,110^{\circ}$ to $930^{\circ} \mathrm{F}$. Obviously, the critical cooling rate of a steel is an index to the stability of its austenite in this temperature range. The slower the critical cooling rate the more stable is its austenite in the temperature range $1,110^{\circ}$ to $930^{\circ} \mathrm{F}$ and the deeper is the hardening.

In the present experiments, the critical cooling rate was taken as the average cooling rate between $1,110^{\circ}$ and $930^{\circ} \mathrm{F}$, which produced in the quenched specimens a structure of martensite with nodular troostite in amounts estimated to be between 1 and 3 percent.

As shown in previous experiments [2] in which specimens of the alloys were quenched directly from $1,800^{\circ} \mathrm{F}$, the $A r^{\prime \prime}$ transformation commenced in some of the alloys at temperatures appreciably higher than in the plain carbon steels used in the interrupted quench experiments of Davenport and Bain. Data on the isothermal transformation of austenite in high-purity iron-carbon alloys would be of particu- 

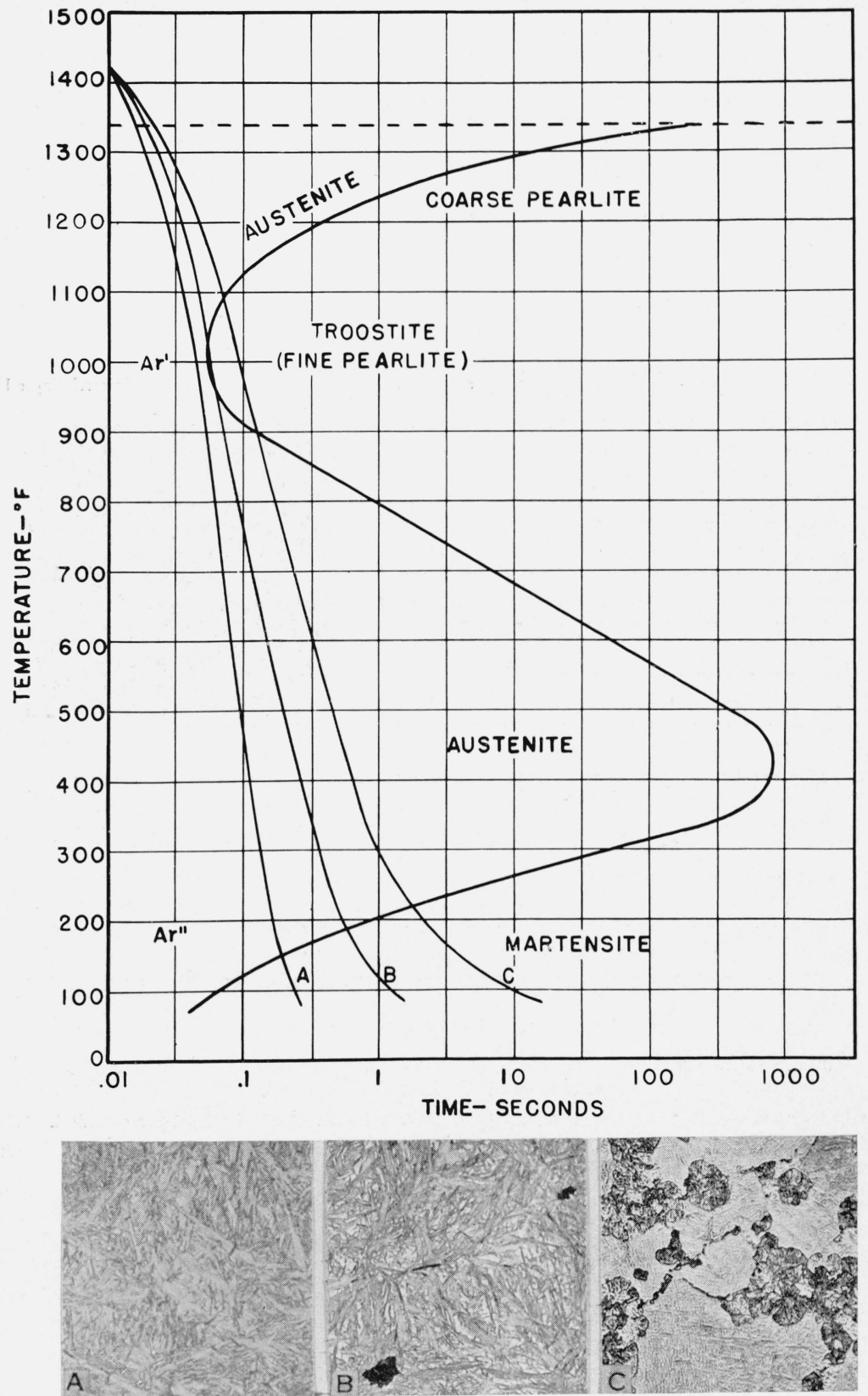

FIGURE 8.-Decomposition of austenite at various temperatures.

The diagram illustrates the method of determining the critical cooling rate and the structures obtained with different cooling rates. $A$, Martensite; $\times 250 . B$, Martensite with small amount of troostite (critical cooling rate); $\times 250$. C, Martensite and troostite; $\times 100$. All specimens etched with 1-percent nital. 


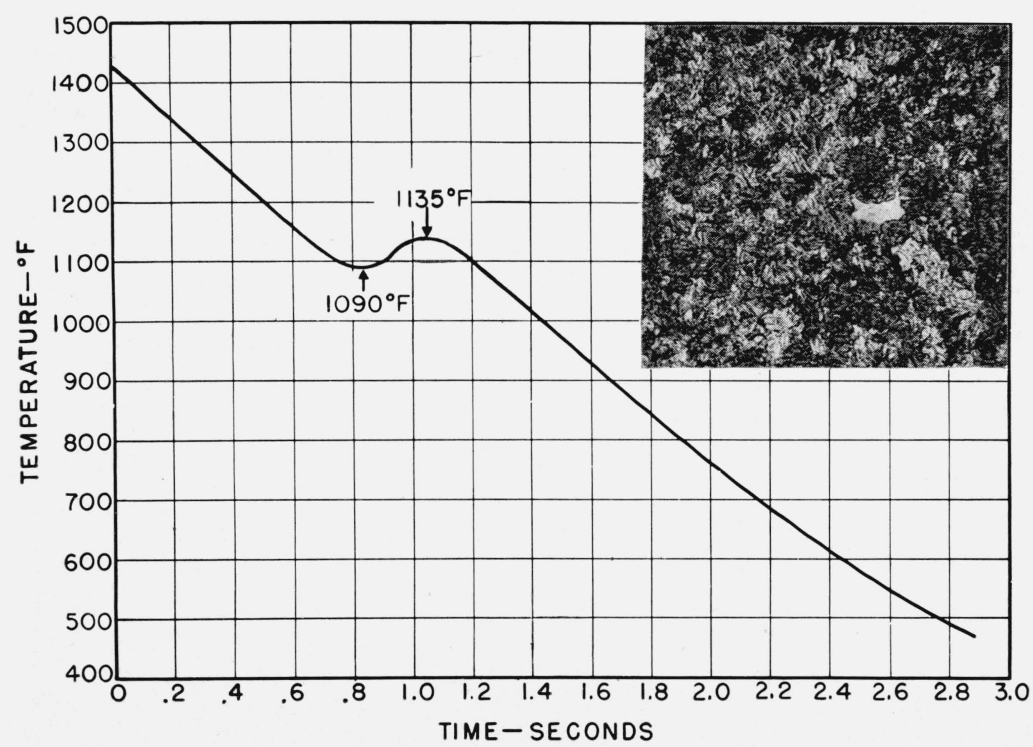

FIgURE 9.-Time-temperature cooling curve and structure of iron-carbon alloy containing 0.80 percent of carbon.

Quenched structure consisted of troostite with a trace of martensite. Etched with 1-percent nital. $\times 100$. 
lar assistance in the determination of the critical cooling rates by definitely establishing the upper range in which the austenite is most likely to decompose. Accurate data on this subject would be difficult to obtain because of the relatively high transformation rates of austenite in high-purity iron-carbon alloys, especially those of the lower carbon contents.

Although the transformation rates of austenite at constant temperature levels were not determined for the alloys, some data obtained in the continuous quench experiments throw light upon the temperatures of the $A r^{\prime}$ and $A r^{\prime \prime}$ transformations. These data for the alloys, ranging in carbon from 0.62 to 1.01 percent, are summarized in table 3 and in figures 9 and 10. In general, the start of the $A r^{\prime}$ occurred within the temperature range of about $1,110^{\circ}$ to $930^{\circ} \mathrm{F}$, provided the specimens were cooled at the most rapid rate possible for the austenite to transform completely to troostite. This fact is shown by the cooling curve and microstructure, reproduced in figure 9 , for a specimen of the 0.80 -percent-carbon alloy quenched directly

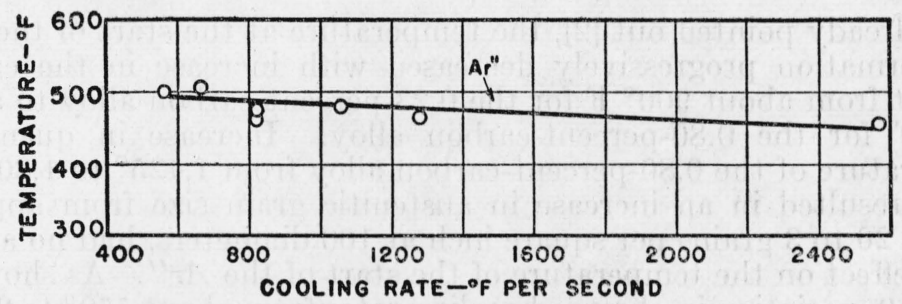

FIGURE 10.-Relation of cooling rate to temperature of the start of Ar $r^{\prime \prime}$ for ironcarbon alloy containing 0.80 percent of carbon quenched from $1,425^{\circ} \mathrm{F}$.

Except for the cooling rate of $560^{\circ} \mathrm{F}$ per second, where a correction was made for the heat effect due to the $A r^{\prime}$ transformation, all cooling rates are based on the average rate required for the specimen to cool through the temperature range of $1,110^{\circ}$ to $930^{\circ} \mathrm{F}$.

from $1,425^{\circ} \mathrm{F}$. The austenite was cooled unchanged to a temperature of about $1,090^{\circ} \mathrm{F}$, which is in the upper portion of the range $1,110^{\circ}$ to $930^{\circ} \mathrm{F}$. At this temperature the austenite started to decompose, as shown by the inflection in the cooling curve, the evolution of heat accompanying the transformation causing a $45^{\circ} \mathrm{F}$ rise in temperature to a maximum of $1,135^{\circ} \mathrm{F}$ in 0.2 second. The transformation of the austenite continued at approximately this temperature for about 0.1 second, and additional transformation of austenite to troostite undoubtedly occurred while the specimen cooled through the $A r^{\prime}$ temperature range. A small proportion of the austenite was cooled to the temperature $\left(A r^{\prime \prime}\right)$ favorable for its transformation to martensite. This is shown by the microstructure of the quenched specimen, which consisted of a trace of martensite in a matrix of troostite. If the cooling rate of the alloy were progressively increased, the proportion of the austenite that transforms in the $A r^{\prime}$ temperature range would be decreased, the heat effect from the $A r^{\prime}$ transformation would be diminished in intensity, and the temperature of the start of $A r^{\prime}$ would be lowered. With a cooling rate that produced 5 to 10 percent of troostite in the 0.80-percent-carbon alloy, the $A r^{\prime}$ started at approximately $1,040^{\circ} \mathrm{F}$. With rates in excess of the critical cooling rate, all the austenite is cooled unchanged through the $A r^{\prime}$ to the $A r^{\prime \prime}$ temperature range. 
TABLE 3.-Temperature of the start of the $A r^{\prime}$ and $A r^{\prime \prime}$ transformations in the iron-carbon alloys

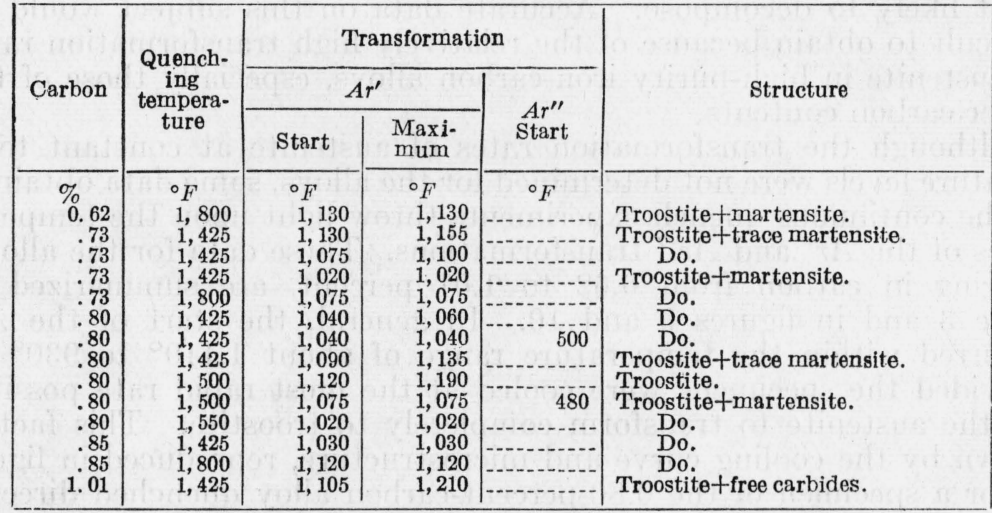

As already pointed out [2], the temperature at the start of the $A r^{\prime \prime}$ transformation progressively decreased with increase in the carbon content from about $900^{\circ} \mathrm{F}$ for the 0.23 -percent-carbon alloy to about $500^{\circ} \mathrm{F}$ for the 0.80 -percent-carbon alloy. Increase in quenching temperature of the 0.80 -percent-carbon alloy from $1,425^{\circ}$ to $1,800^{\circ} \mathrm{F}$, which resulted in an increase in austenitic grain size from approximately 20 to 3 grains per square inch at 100 diameters, had no appreciable effect on the temperature of the start of the $A r^{\prime \prime}$. As shown in figure 10, variation in observed cooling rates from about $550^{\circ}$ to $2,600^{\circ}$ $F$ per second had no appreciable influence on the temperature range of the start of the $A r^{\prime \prime}$ transformation in the 0.80-percent-carbon alloy.

The difficulty of accurate measurements of the isothermal transformation of austenite in the alloys is well illustrated by the cooling curve of figure 9 . The specimen, containing 0.80 percent of carbon, was cooled from the quenching temperature of $1,425^{\circ} \mathrm{F}$ to below $1,000^{\circ} \mathrm{F}$ in less than 1.5 seconds. This elapsed time was sufficient for the austenite to decompose to troostite. With austenite of lower carbon content, or smaller grain size, the reaction time is less than that shown for the 0.80-percent-carbon alloy.

The position of the bend in the S-curve (at $1,110^{\circ}$ to $930^{\circ} \mathrm{F}$ ) for the alloys is not accurately defined by these data (table 3, figs. 9 and 10). Although desirable, it is not entirely essential that the location of this temperature range be known for use in the determination of the critical cooling rate of the alloys because of the exponential type of cooling curve obtained by quenching the specimens in a gas. In any event, the relation of the critical cooling rate to the several variables studied would have been similar if some other temperature interval within the limits of approximately $1,150^{\circ}$ to $900^{\circ} \mathrm{F}$ had been selected for the determination of the critical cooling rate of the alloys.

1. The influence of variations in quenching rate on the rate of transformation of austenite, and on the hardness of the alloy containing 0.80 percent of carbon, are summarized in figure 11. At the quenching temperature of $1,425^{\circ} \mathrm{F}$, all the specimens had approximately the same average grain size and the carbon was completely dissolved. With a cooling rate of $450^{\circ} \mathrm{F}$ per second, the austenite transformed in the $A r^{\prime}$ temperature range, whereas with a rate of $560^{\circ} \mathrm{F}$ per second, less than 10 percent of the austenite decomposed at $A r^{\prime}$. With further 
progressive increase in cooling rate, the estimated proportion of the austenite that transformed in the $A r^{\prime}$ temperature range progressively decreased until none of the austenite transformed in this temperature range. Thus, there is a narrow range in quenching rates in which the austenite of high-purity iron-carbon alloys transforms at $A r^{\prime}$ and a wide range in quenching rates in which the larger portion of the austenite transforms at $A r^{\prime \prime}$. Critical-cooling-rate values, by definition, are restricted to the latter range in cooling rates. As shown by the slope of the transformation-cooling-rate curve for the upper range of cooling rates, wide changes in cooling rates result in only minor changes in the proportion of troostite. For example, an increase in quenching rate from about 1,000 to $1,280^{\circ} \mathrm{F}$ per second decreased the

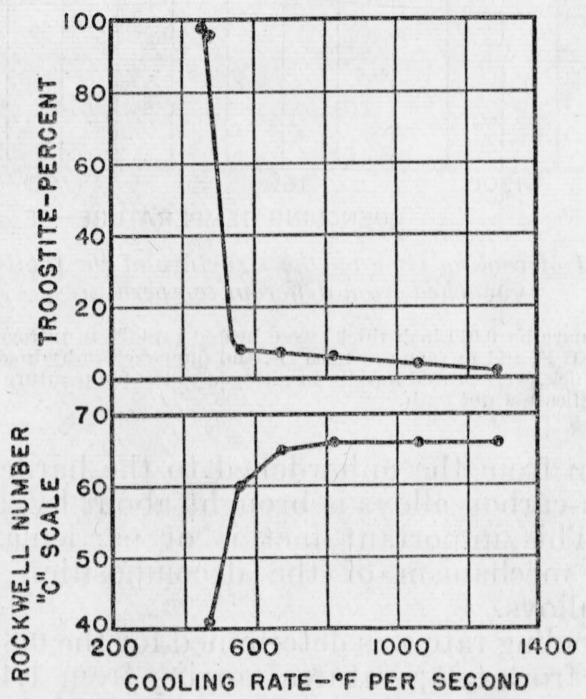

FIGURE 11.-Effect of cooling rate on structure and hardness of iron-carbon alloy containing 0.80 percent of carbon quenched from $1,425^{\circ} \mathrm{F}$.

Except for cooling rates ranging from $450^{\circ}$ to $560^{\circ} \mathrm{F}$ per second where corrections were made for the heat effect due to the $A r^{\prime}$ transformation, all cooling rates are based on the a verage rate required for the specimen to cool through the temperature range of 1,110 to $930^{\circ} \mathrm{F}$. Hardness values were obtained on the flat surface of the quenched specimens.

estimated amounts of troostite only from 5 to 2 percent. This fact should be borne in mind when the critical cooling rate is used as the basis for a comparison of the hardenability of the alloys.

The hardness of the quenched specimens increased from Rockwell $C 40$ to 65 as the cooling rate was increased from about $450^{\circ}$ to $680^{\circ} \mathrm{F}$ per second. Further increase in quenching rate had no marked effect on the hardness of the alloy. Thus, appreciable proportions of troostite may be produced in the quenched specimens without its presence being indicated by hardness testing. This is shown by the difference in the slope of the two curves in figure 11, for the upper range of quenching rates. The Rockwell test indicated that the alloy was completely hardened when the specimens contained troostite varying in amounts up to approximately 6 percent. A similar relation was also shown in microhardness testing. Obviously the hardness values alone, obtained on the quenched specimens, could not be used as a precise index of the actual cooling rate of the specimens. 


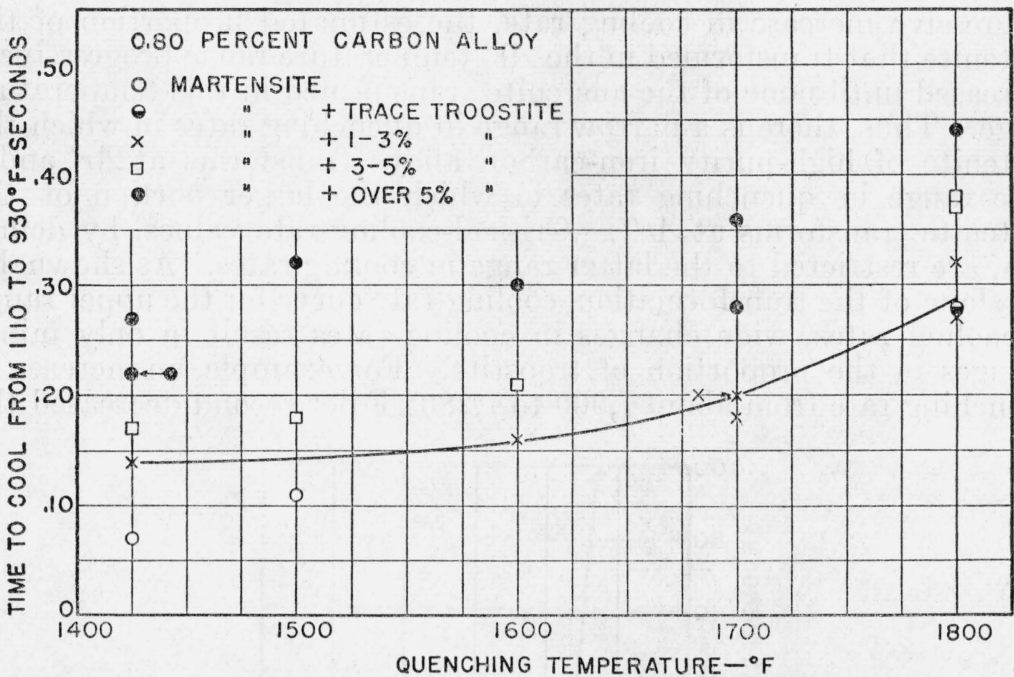

Figure 12.-Effect of cooling time on the structure of the 0.80-percent-carbon alloy quenched from different temperatures.

Specimens, 0.10 inch square by 0.040 inch thick, were heated rapidly in nitrogen to the temperatures of $1,425^{\circ}, 1,500^{\circ}$, and $1,600^{\circ} \mathrm{F}$, and in vacuo to $1,800^{\circ} \mathrm{F}$, and quenched in hydrogen specimens, 0.25 inch square by 0.040 inch thick, were heated rapidly in nitrogen to the temperature of $1,700^{\circ} \mathrm{F}$ and quenched directly in a sodium-silicate-water bath.

The transition from the unhardened to the hardened condition in high-purity iron-carbon alloys is brought about by a small change in cooling rate. This important fact is of particular significance in considering the mechanism of the decomposition of austenite on quenching the alloys.

The critical cooling rate was determined for the 0.80 -percent-carbon alloy quenched from temperatures ranging from $1,425^{\circ}$ to $1,800^{\circ} \mathrm{F}$,

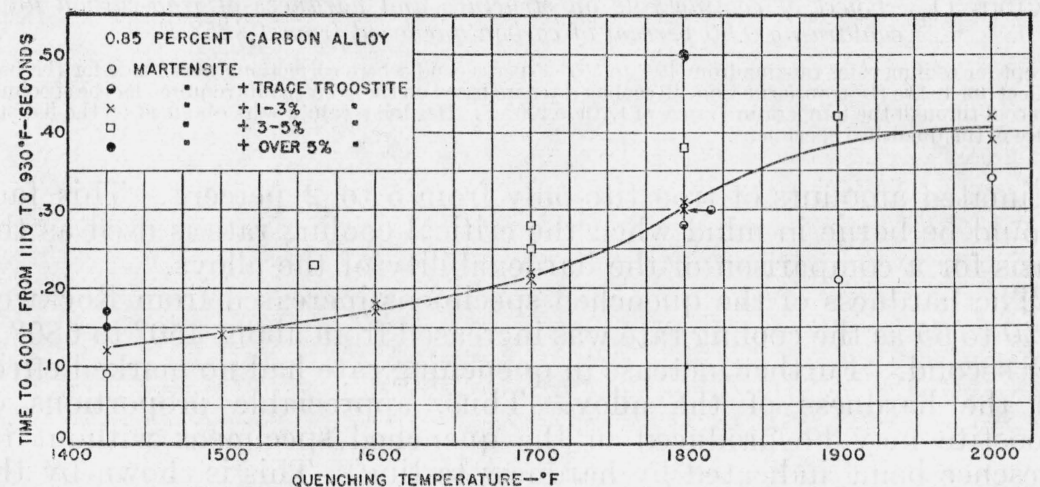

FIGURE 13.-Effect of cooling time on the structure of the 0.85-percent-carbon alloy quenched from different temperatures.

Specimens, $0.10 \mathrm{inch}$ square by $0.040 \mathrm{inch}$ thick, were heated rapidly in nitrogen to the temperatures of $1,425^{\circ}$, $1,500^{\circ}$, and $1,600^{\circ} \mathrm{F}$, and in vacuo to $1,800^{\circ}, 1,900^{\circ}$, and $2,000^{\circ} \mathrm{F}$, and quenched in hydrogen. Specimens 0.25 inch square by 0.040 inch thick, were heated rapidly in nitrogen to $1,700^{\circ} \mathrm{F}$ and quenched in a sodiumsilicate-water bath. 


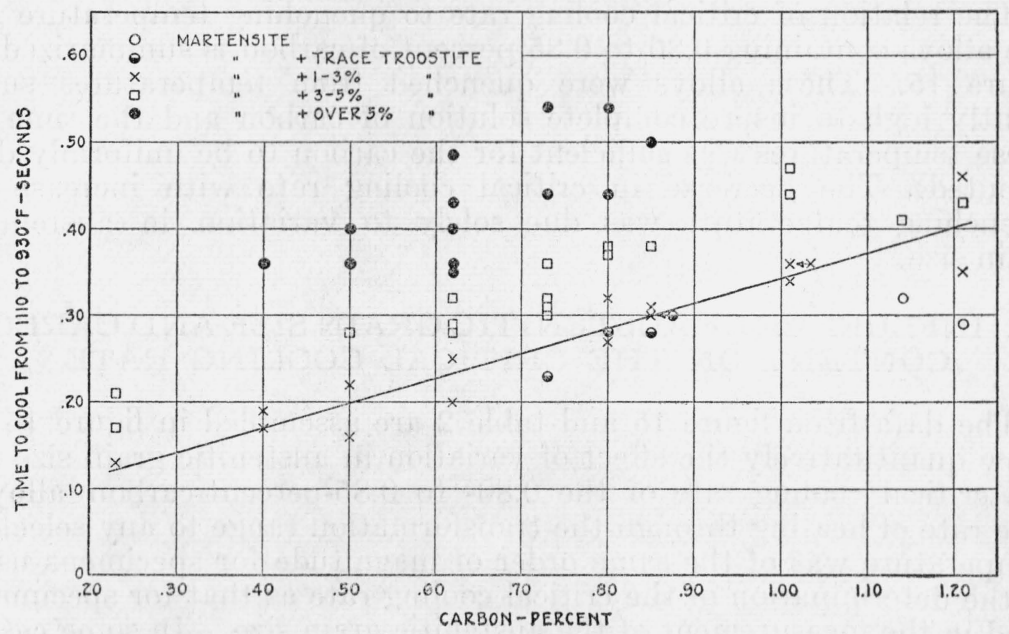

FIGURE 14.-Effect of cooling time on the structure of iron-carbon alloys.

Specimens were heated rapidly in vacuo to $1,800^{\circ} \mathrm{F}$ and quenched directly in hydrogen. At $1,800^{\circ} \mathrm{F}$, all the alloys had the same average grain size of 2.9 grains per square inch at 100 diameters (table 2), and the carbon was completely dissolved.

for the 0.85-percent-carbon alloy quenched from temperatures ranging from $1,425^{\circ}$ to $2,000^{\circ} \mathrm{F}$, and for the other alloys ranging in carbon from 0.23 to 1.21 percent quenched from $1,800^{\circ} \mathrm{F}$.

The effect of the time to cool from $1,110^{\circ}$ to $930^{\circ} \mathrm{F}$ on the structure of the 0.80 -percent-carbon alloy quenched from various temperatures is shown in figure 12 , and on the 0.85 -percent-carbon alloy in figure 13 . The effect of time to cool from $1,110^{\circ}$ to $930^{\circ} \mathrm{F}$ on the structure of the alloys, varying in carbon content, quenched from $1,800^{\circ} \mathrm{F}$ is shown in figure 14. The relation of critical cooling time (resulting in 1 to 3 percent of troostite) to quenching temperature is represented by the curves in figures 12 and 13 , and to carbon content in figure 14 .

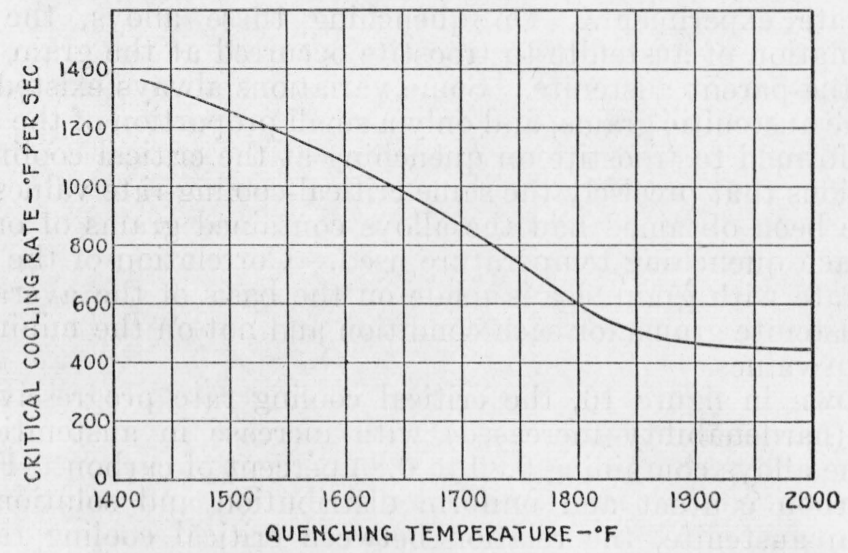

FrguRE 15.-Relation of critical cooling rate to quenching temperature of ironcarbon alloys containing 0.80 to 0.85 percent of carbon.

The austenitic grain size ranged from approximately 20 to $11 / 2$ grains per square inch at 100 diameters. 
The relation of critical cooling rate to quenching temperature for the alloys containing 0.80 to 0.85 percent of carbon is summarized in figure 15. These alloys were quenched from temperatures sufficiently high to insure complete solution of carbon and the time at these temperatures was sufficient for the carbon to be uniformly distributed. The decrease in critical cooling rate with increase in quenching temperature was due solely to variation in austenitic grain size.

\section{INFLUENCE OF AUSTENITIC GRAIN SIZE AND CARBON CONTENT ON THE CRITICAL COOLING RATE}

The data from figure 15 and table 2 are assembled in figure 16 to show quantitatively the effect of variation in austenitic grain size on the critical cooling rate of the 0.80 - to 0.85 -percent-carbon alloys. The rate of heating through the transformation range to any selected temperature was of the same order of magnitude for specimens used in the determination of the critical cooling rate as that for specimens used in the measurement of the austenitic grain size. In some cases, the grain size was determined on the specimens used in the critical-

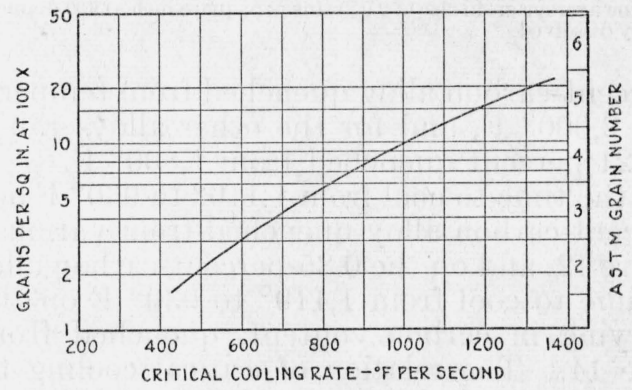

FigURE 16. - Relation of critical cooling rate to austenitic grain size of iron-carbon alloys containing 0.80 to 0.85 percent of carbon.

cooling-rate experiments. On quenching these alloys, the initial transformation of austenite to troostite occurred at the grain boundaries of the parent austenite. Some variations always existed in the size of the austenitic grains, and only a small proportion of the austenite transformed to troostite on quenching at the critical cooling rate. It is obvious that precisely the same critical-cooling-rate values would not have been obtained had the alloys contained grains of only one size at each quenching temperature used. Correlation of the critical cooling rate with grain size is made on the basis of the average size of the austenite grains for each condition and not on the minimum or maximum values.

As shown in figure 16, the critical cooling rate progressively decreased (hardenability increased) with increase in austenitic grain size of the alloys containing 0.80 to 0.85 percent of carbon. For constant carbon content and uniform distribution and solution of all carbon in austenite, the relation between critical cooling rate and austenitic grain size may be represented approximately by the empirical equation

$$
R=\text { constant }(N)^{n},
$$


where $R$ is the critical cooling rate in ${ }^{\circ} \mathrm{F}$ per second, $N$ is the number of austenitic grains per square inch at 100 diameters, and $n$ is constant and equals approximately 0.4 .

The basis for this equation is the fact that graphs of relationship between grain size and critical cooling rate, on logarithmic scale, are approximately straight lines.

The relation of critical cooling rate to carbon content of the alloys for two different austenitic grain sizes is shown in figure 17. The results summarized in curve $A$ were obtained in previous experiments [1] by quenching specimens directly from $1,700^{\circ} \mathrm{F}$, the temperature

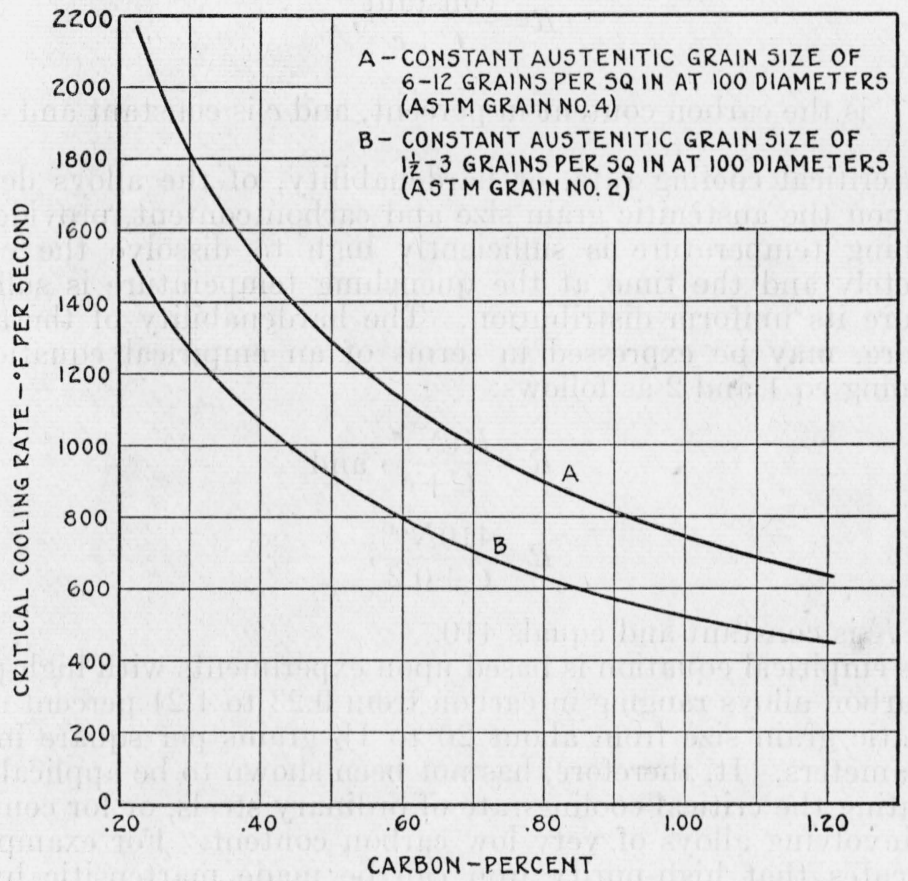

FIGURE 17.--Relation of critical cooling rate to carbon content of iron-carbon alloys.

establishing an average constant grain size of approximately 7.5 grains per square inch at 100 diameters with all carbon in solution. The results summarized in curve $B$ were obtained in the present experiments (fig. 14) by quenching specimens directly from $1,800^{\circ} \mathrm{F}$, the temperature establishing an average constant austenitic grain size of approximately 2.9 grains per square inch at 100 diameters with all carbon in solution (see table 2 for grain size of the alloys at $1,700^{\circ}$ and $\left.1,800^{\circ} \mathrm{F}\right)$.

The influence of austenitic grain size on the hardenability of the alloys is also shown by a comparison of the results summarized in curves $A$ and $B$. With any selected carbon content within the range of 0.23 to 1.21 percent, the ratio of the critical cooling rate for an average austenitic grain size of 7.5 grains per square inch at 100 diameters to that for an average austenitic grain size of 2.9 grains per square inch at 100 diameters was approximately constant and was of the 
order of 1.43 to 1.0. That is, in order to attain complete hardening, an alloy with the smaller austenitic grains must be cooled approximately 1.5 times as fast as the same alloy with the larger grains.

For each austenitic grain size investigated (fig. 17), the critical cooling rate decreased continuously with increase in carbon content of the alloys. For constant austenitic grain size and uniform distribution and solution of all carbon in austenite, the relation between critical cooling rate and carbon content of the alloys may be approximately represented by the empirical equation

$$
R=\frac{\text { constant }}{C+c}
$$

where $C$ is the carbon content in percent, and $c$ is constant and equals 0.2 .

The critical cooling rate, or hardenability, of the alloys depends only upon the austenitic grain size and carbon content, provided the quenching temperature is sufficiently high to dissolve the carbon completely and the time at the quenching temperature is sufficient to insure its uniform distribution. The hardenability of the alloys, therefore, may be expressed in terms of an empirical equation by combining eq 1 and 2 as follows:

$$
\begin{aligned}
& R=\frac{K(N)^{n}}{C+c}, \text { and } \\
& R=\frac{410 N^{\cdot 4}}{C+0.2},
\end{aligned}
$$

where $K$ is constant and equals 410 .

This empirical equation is based upon experiments with high-purity iron-carbon alloys ranging in carbon from 0.23 to 1.21 percent and in austenitic grain size from about 20 to $1 \frac{1}{2}$ grains per square inch at 100 diameters. It, therefore, has not been shown to be applicable for computing the critical cooling rate of ordinary steels, or for computations involving alloys of very low carbon content. For example, eq 4 indicates that high-purity iron can be made martensitic by fast quenching, obviously a condition that is impossible. It should be pointed out that the determinations for carbon were made with considerably more precision than was possible in the determinations of the austenitic grain size of the alloys.

\section{SURFACE HARDNESS}

French and Klopsch [4] reported the results of Rockwell hardness tests made on specimens of carbon steels varying in carbon content and quenched at different rates. For specimens quenched at the critical cooling rate, hardness increased rapidly with carbon content up to about 0.70 percent but thereafter remained constant with increase in carbon. With steels containing 0.75 to 1.25 percent of carbon, practically identical hardness values were obtained on the quenched specimens containing appreciable proportions of troostite and on the completely martensitic specimens. In 1938, Burns, Moore, and Archer [11] showed that the maximum hardness attainable by quenching the 
plain carbon and common alloy steels depends alone on the carbon content. The hardness values (Rockwell $C$ ) increased with carbon up to about 0.55 percent and thereafter remained constant with increase in carbon (for the range in carbon investigated).

In the present investigation, readings for hardness were made with the Rockwell Superficial tester (30-kg load) on most of the specimens used in the determination of the critical cooling rate of the alloys. For comparison purposes, the readings were converted to the $C$ scale in accordance with the conversion tables supplied by the manufacturer of the instrument. The flat surfaces of the quenched specimens were cleaned with $1 G$ emery paper before testing.

The results of the hardness tests made on specimens of the alloys quenched directly from $1,800^{\circ} \mathrm{F}$ at various rates are summarized in figure 18. The estimated amounts of troostite formed (1 to 3 percent for critical cooling rate) are also shown, together with the curve

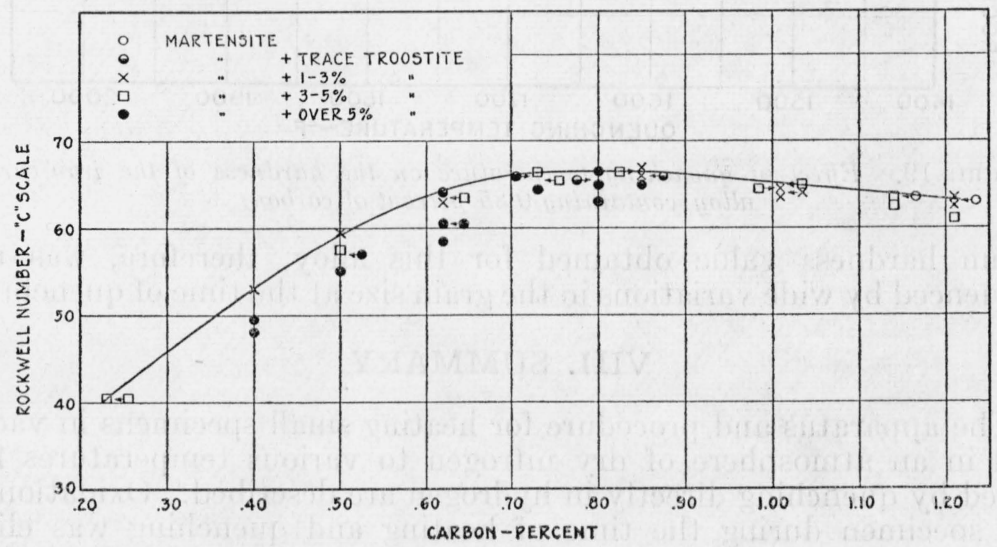

Figure 18.-Effect of carbon content on the hardness of iron-carbon alloys.

representing the relation of maximum values obtained for hardness to carbon content.

The alloys had the same average grain size of 2.9 grains per square inch at 100 diameters and all carbon was in solution at the time of quenching, but not all the specimens were completely martensitic after the quench as evidenced by the presence of troostite. The latter specimens, with troostite estimated up to 5 percent, had Rockwell hardness values of the same order of magnitude as the fully martensitic specimens of similar carbon content. The maximum hardness values obtained increased with increase in carbon up to about 0.70 percent, remained constant for alloys ranging in carbon from 0.70 to 0.85 percent, and decreased slightly with further increase in carbon. The decrease in hardness with increase in carbon of the alloys in the highcarbon range is believed to be due to the retention of some austenite after the quench. The maximum hardness values obtained for the alloys in the low-carbon range are considerably lower than those reported by Burns, Moore, and Archer [11] for steels of similar carbon content, whereas in the high-carbon range the alloys had approximately the same hardness values as the steels. 
As is shown in figure 19, the maximum hardness value for the 0.85 percent-carbon alloy was not affected by variation in quenching temperatures from $1,425^{\circ}$ to $2,000^{\circ} \mathrm{F}$. This range in quenching temperatures produced austenitic grain sizes ranging from approximately 20 to $1 \frac{1}{2}$ grains per square inch at 100 diameters (table 2). The max-

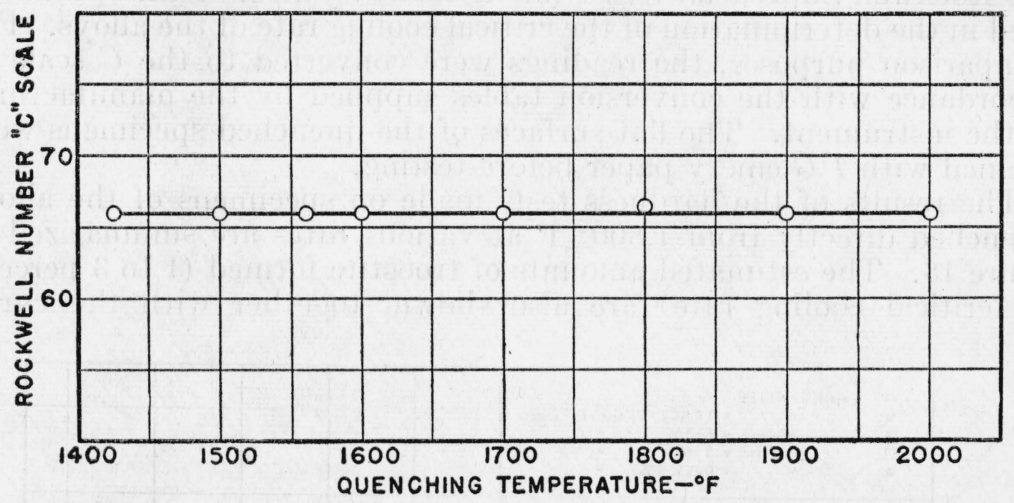

Figdre 19.-Effect of quenching temperature on the hardness of the iron-carbon alloy containing 0.85 percent of carbon.

imum hardness value obtained for this alloy, therefore, was not influenced by wide variations in the grain size at the time of quenching.

\section{SUMMARY}

The apparatus and procedure for heating small specimens in vacuo and in an atmosphere of dry nitrogen to various temperatures followed by quenching directly in hydrogen are described. Oxidation of the specimen during the time of heating and quenching was eliminated, and it was possible to obtain progressive changes in cooling rates over the wide range required in the present experiments. Specimens quenched in hydrogen were cooled uniformly over the entire surface, as shown by the microstructure in the cross section.

The string-galvanometer apparatus and the procedure used for obtaining photographic records of the time-temperature cooling curves are also described in some detail. Examples are given of typical cooling curves obtained on specimens heated in vacuo and in an atmosphere of dry nitrogen and quenched directly in hydrogen.

The high-purity iron-carbon alloys used in the present study ranged in carbon from 0.23 to 1.21 percent. The specimens were from the same alloys as those used and described in previous investigations [1,2].

The grain size established at temperatures ranging from $1,425^{\circ}$ to $1,600^{\circ} \mathrm{F}$ increased markedly with decrease in rate of heating through the transformation range, whereas the grain size at $1,800^{\circ} \mathrm{F}$ was not so noticeably dependent upon the rate of heating. The grain sizes at temperatures ranging from $1,425^{\circ}$ to $2,100^{\circ} \mathrm{F}$ was determined for the alloys. For any selected temperatures within the range from $1,600^{\circ}$ to $2,100^{\circ} \mathrm{F}$ and with the heating rate employed, all the alloys were found to have approximately the same average grain size provided the carbon was completely dissolved at that temperature. Carbon in solution, therefore, was not effective in inhibiting grain growth of 
the austenite in the high-purity iron-carbon alloys. The actual temperatures and the rate of heating through the transformation range were the dominant factors in controlling the austenitic grain size of these alloys.

There is a narrow range in cooling rates in which the austenite transforms at $A r^{\prime}$ and a wide range in quenching rates in which the larger portion of the austenite transforms at $A r^{\prime \prime}$. Thus, the transition from the unhardened to the hardened condition in high-purity iron-carbon alloys is brought about by a small change in cooling rate.

The critical cooling rate was determined for the 0.80 -percentcarbon alloy quenched directly from temperatures ranging from $1,425^{\circ}$ to $1,800^{\circ} \mathrm{F}$, for the 0.85 -percent-carbon alloy quenched from temperatures ranging from $1,425^{\circ}$ to $2,000^{\circ} \mathrm{F}$, and for the alloys varying in carbon from 0.23 to 1.21 percent quenched from $1,800^{\circ} \mathrm{F}$.

The critical cooling rate was taken as the average cooling rate, between $1,110^{\circ}$ and $930^{\circ} \mathrm{F}$, which produced in the quenched specimen a structure of martensite with nodular troostite (fine pearlite) in amounts estimated to be between 1 and 3 percent.

The critical cooling rate progressively decreased (hardenability increased) as the austenitic grain size increased in the alloys containing 0.80 to 0.85 percent of carbon. For each austenitic grain size investigated, the critical cooling rate decreased continuously with increase in carbon content of the alloys.

For complete solution and uniform distribution of carbon at the time of quenching, the critical cooling rate ( $R$ in ${ }^{\circ} \mathrm{F}$ per second) or hardenability of the alloys may be approximately represented by the equation

$$
R=\frac{410 N^{.4}}{C+0.2},
$$

where $N$ is the number of austenitic grains per square inch at 100 diameters and $C$ is the carbon content in percent.

Hardness values obtained on the quenched specimens could not alone be used as a precise index to the actual cooling rates of the alloys.

The maximum hardness values obtained on specimens of each alloy quenched from $1,800^{\circ} \mathrm{F}$ increased with increase in carbon up to about 0.70 percent, remained constant for alloys ranging from 0.70 to 0.85 percent, and decreased slightly with further increase in carbon. The maximum hardness value for the 0.85 -percent-carbon alloy was not affected by variation in quenching temperatures from $1,425^{\circ}$ to $2,000^{\circ} \mathrm{F}$. This range in quenching temperatures produced in the alloy austenitic grain sizes ranging from approximately 20 to $1 \frac{11}{2}$ grains per square inch at 100 diameters.

Variation in observed cooling rates from about $550^{\circ}$ to $2,600^{\circ} \mathrm{F}$ per second with austenitic grain size of approximately 20 grains per square inch at 100 diameters had no appreciable influence on the temperature range of the start of the $A r^{\prime \prime}$ transformation in the 0.80 -percent-carbon alloy. Variation in austenitic grain size ranging from approximately 20 to 3 grains per square inch at 100 diameters 
had no detectable effect on the temperature of the start of the $A r^{\prime \prime}$ in this alloy.

Grateful acknowledgment is made to N. L. Carwile and S. J. Rosenberg for assistance in this work.

\section{REFERENCES}

[1] Thomas G. Digges, Effect of carbon on the critical cooling rate of high-purity iron-carbon alloys and plain carbon steels, J. Research NBS 20, 571 (1938) RP1092. Also, Effect of carbon on the hardenability of high-purity ironcarbon alloys, Trans. Am. Soc. Metals 26, 408 (1938).

[2] Thomas G. Digges, Transformation of austenite on quenching hrgh-purity iron-carbon alloys, J. Research NBS 23, 151 (1939) RP1225. Also, Preprint 24. Paper presented at twenty-first annual convention of the Am. Soc. Metals (Oct. 23-27, 1939).

[3] Zay Jeffries, Am. Soc. Testing Materials, Standards, pt. 1, Metals, Designation E2-36 (Note 2) p. 763 (1936).

[4] H. J. French and O. Z. Klopsch, Quenching diagrams for carbon steels in relation to some quenching media for heat treatment, Trans. Am. Soc. Steel Treating 6, 251 (1924).

[5] Carl L. Shapiro, What about grain size? Iron Age 143, 25, March 16; 23, March 30;33, April 6 (1939).

[6] N. F. Ward and J. E. Dorn, Grain size of steel, Metals \& Alloys 10, 74, 115, 212,246 (1939).

[7] G. Derge, A. R. Kommel, and R. F. Mehl, Some factors influencing austenitic grain size in high-purity steels, Trans. Am. Soc. Metals 26, 153 (1938).

[8] M. A. Grossmann, On grain size and grain growth, Trans. Am. Soc. Steel Treating 21, 1079 (1933).

[9] E. S. Davenport and E. C. Bain, Transformation of austenite at constant subcritical temperatures, Trans. Am. Inst. Min. \& Met. Engrs., Iron \& Steel Div. 90, 117 (1930).

[10] A contribution form the Research Laboratory, United States Steel Corporation, The process and results of austenite transformation at constant temperature, Metals \& Alloys, 8, 22 (1937).

[11] J. L. Burns, T. L. Moore, and R. S. Archer, Quantitative hardenability, Trans. Am. Soc. for Metals 26, 1 (1938).

Washington, February 13, 1940. 